\title{
In C Language How to Use Pointer to Access Two-Dimensional Array Element
}

\author{
WeiQing Bai \\ College of Software and Technology \\ QingDao University \\ QingDao, China \\ bwqsyt@sina.com
}

\begin{abstract}
In C language, it is difficult to use the pointer to access the two-dimensional array element. The reason is the addresses of two-dimensional array are many, pointers that can access the two-dimensional array element are many and complex. This paper analyzes the twodimensional array address and pointer, introduces various forms of using pointer to express two-dimensional array element, explains the relationship between pointer and two-dimensional array address. The program examples show how to use pointers to access the two-dimensional array element.
\end{abstract}

Keywords-c language; two-dimensional array; address; pointer

\section{INTRODUCTION}

In $\mathrm{C}$, to learn pointer is difficult, students use pointer to access two-dimensional array element feel especially difficult. The reason is the addresses of twodimensional array are many, pointers that can access the two-dimensional array element are many and complex. In order to solve this problem, this paper first analyzes the address of one-dimensional array and how to use pointer to express one dimensional array element. Based on this, it further analyzes the two-dimensional array address and pointer, introduces various forms of using pointer to express two-dimensional array element, explains the relationship between the pointer and twodimensional array address.

\section{ONE-DIMENSIONAL ARRAY AND POINTER}

A one-dimensional array and a pointer which points to one-dimensional array are defined as follows: ${ }^{[1]}$

$$
\text { int } \mathrm{a}[10],{ }^{*} \mathrm{p} \text {; }
$$

A. the Address of One-dimensional Array One-dimensional array involves the following address:

(1) the address of array element:\&a[i] $(0 \leq \mathrm{i} \leq 9)$

(2) array name a, the name of an array is a synonym for the location of the initial element: $\mathrm{a}==\& \mathrm{a}[0]$.

B. the Pointer Variables Related With the Onedimensional Array

If $\mathrm{p}$ is a pointer to an integer, defined as: int $* \mathrm{p}$; then the assignment $\mathrm{p}=\& \mathrm{a}[0]$ sets $p$ to point to element zero of a, we can access the array element through pointer $\mathrm{p}$.

\section{Various Forms of One-dimensional Array Element Address}

We can use subscript or pointer to express onedimensional array element address, there has the following four kind of representation:

(1) subscript method : \&a[i]

(2) array name method: $\mathrm{a}+\mathrm{i}$

(3) pointer method: $\mathrm{p}+\mathrm{i}$

(4) pointer subscript method:\&p[i]

D. Various Forms of One-dimensional Array Element

We can use subscript or pointer to express onedimensional array element, there has the following four kind of representation:

(1) subscript method : $\mathrm{a}[\mathrm{i}]$

(2) array name method: $*(a+i)$

(3) pointer method:*(p+i)

(4) pointer subscript method:p[i]

One-dimensional array is the basis of learning twodimensional array, if we understand the relationship between pointer and one- dimensional array, then we can easily understand the relationship between pointer and two- dimensional array.

\section{TWO-DIMENSIONAL ARRAY AND POINTER}

A two-dimensional array is defined as follows: ${ }^{[1]}$ int a[3][4];

\section{A. the Address of Two-dimensional Array}

In c, a two-dimensional array is really a onedimensional array, each of whose elements is a onedimensional array. For example, two-dimensional array a has three elements $\mathrm{a}[0] 、 \mathrm{a}[1] 、 \mathrm{a}[2]$, from the knowledge of one-dimensional array we know that a and $\& \mathrm{a}[0]$ are equivalent, $\mathrm{a}+1$ and $\& \mathrm{a}[1]$ are equivalent, $\mathrm{a}+2$ and $\& \mathrm{a}[2]$ are equivalent.

We can sum up that $\mathrm{a}+\mathrm{i}$ and $\& \mathrm{a}[\mathrm{i}]$ are equivalent $(0 \leq \mathrm{i} \leq 2)$, therefore $*(\mathrm{a}+\mathrm{i})$ and $\mathrm{a}[\mathrm{i}]$ are equivalent. $\mathrm{A}+\mathrm{i}$ and $\& \mathrm{a}[\mathrm{i}]$ are starting address of each row in the array, they are called row address. ${ }^{[2]}$

Each element of array a is a one-dimensional array, such as $a[0][4] 、 a[1][4] 、 a[2][4]$, wherein $a[0] 、 a$ [1] $\mathrm{a}[2]$ can be regarded as the name of the one- 
dimensional array. Therefore, $\mathrm{a}[0]$ and $\& \mathrm{a}[0][0]$ are equivalent, $\mathrm{a}[0]+1$ and $\& \mathrm{a}[0][1]$ are equivalent, $\mathrm{a}[0]+2$ and $\& \mathrm{a}[0][2]$ are equivalent, $\mathrm{a}[0]+3$ and $\& \mathrm{a}[0][3]$ are equivalent.

$\mathrm{a}[1]$ and \&a[1][0] are equivalent, $\mathrm{a}[1]+1$ and $\& \mathrm{a}[1][1]$ are equivalent, $\mathrm{a}[1]+2$ and $\& \mathrm{a}[1][2]$ are equivalent, a[1]+3 and \&a[1][3] are equivalent.

$\mathrm{a}[2]$ and $\& \mathrm{a}[2][0]$ are equivalent, $\mathrm{a}[2]+1$ and $\& \mathrm{a}[2][1]$ are equivalent, $\mathrm{a}[2]+2$ and $\& \mathrm{a}[2][2]$ are equivalent, a[2]+3 and $\& \mathrm{a}[2][3]$ are equivalent.

We can sum up that $\mathrm{a}[\mathrm{i}]$ and $\& \mathrm{a}[\mathrm{i}][0]$ are equivalent, $\mathrm{a}[\mathrm{i}]+\mathrm{j}$ and $\& \mathrm{a}[\mathrm{i}][\mathrm{j}]$ are equivalent $(0 \leq \mathrm{i} \leq 2, \quad 0 \leq \mathrm{j} \leq 3)$. $*(\mathrm{a}+\mathrm{i}) 、 \mathrm{a}[\mathrm{i}] 、 \mathrm{a}[\mathrm{i}]+\mathrm{j} 、 \& \mathrm{a}[\mathrm{i}][\mathrm{j}]$ are array element address, they are called element address.

Through the analysis that a and \&a[0] and *a and $\mathrm{a}[0]$ and $\& \mathrm{a}[0][0]$ have identical values, but they mean different meaning. A and $\& \mathrm{a}[0]$ are the address of row zero of the array, *a and $\mathrm{a}[0]$ and $\& \mathrm{a}[0][0]$ are the address of element of column zero of row zero .

$\mathrm{A}+\mathrm{i}$ and $\& \mathrm{a}[\mathrm{i}]$ and $*(\mathrm{a}+\mathrm{i})$ and $\mathrm{a}[\mathrm{i}]$ and $\& \mathrm{a}[\mathrm{i}][0]$ have identical values, but they mean different meaning. $\mathrm{A}+\mathrm{i}$ and $\& a[i]$ are the address of row $\mathrm{i}$ of the array, $*(\mathrm{a}+\mathrm{i})$ and $\mathrm{a}[\mathrm{i}]$ and $\& \mathrm{a}[\mathrm{i}][0]$ are the address of element of column zero of row $\mathrm{i}$.

Those who need a specification is that $\mathrm{a}[\mathrm{i}]$ is not an actual variable, \&a[i] is just a calculated address, is the address of row i. $*(a+i)$ is not the content of $a+i$, is a form of the address.

In summary, the address of two-dimensional array is divided into row address and element address two categories.

1) Row Address

There are two forms of row address:
(1) $\mathrm{a}+\mathrm{i}$
(2) \&a[i]

The name of two-dimensional array is the address of row zero, $\mathrm{a}==\& \mathrm{a}[0]$.

2) Element Address

There are several forms of element address: ${ }^{[3]}$
(1) $\mathrm{a}[\mathrm{i}]+\mathrm{j}$
(3) $\& \mathrm{a}[\mathrm{i}][0]+\mathrm{j}$
(2) $*(a+i)+j$
(5) $\&(*(a+i))[j]$
(4) $\& \mathrm{a}[\mathrm{i}][\mathrm{j}]$
(7) $\mathrm{a}[0]+4 * \mathrm{i}+\mathrm{j}$
(6) $\&(\& \mathrm{a}[\mathrm{i}][0])[\mathrm{j}]$
(9) $* \mathrm{a}+4 * \mathrm{i}+\mathrm{j}$
(8) $\& \mathrm{a}[0][0]+4 * \mathrm{i}+\mathrm{j}$

Among them, (1) (6) are the form of twodimensional, (7) (9) are the form of one-dimensional.

\section{B. the Pointer Variables Related With the Two- dimensional Array}

The pointer variables related with the twodimensional array are many, will be introduced below.

1) the Pointer Variables Which Point to the Twodimensional Array Element

The pointer variable which points to the twodimensional array element is defined as: int a[3][4], ${ }^{*} \mathrm{p}$;

a) Assignment
Pointer $p$ points to the element of column zero of row zero of the two-dimensional array, the correct assignment is:

$$
\begin{aligned}
& \mathrm{p}=\mathrm{a}[0] ; \text { or } \mathrm{p}=* \mathrm{a} ; \text { or } \mathrm{p}=\& \mathrm{a}[0][0] \text {; } \\
& \text { the wrong assignment is: } \\
& \mathrm{p}=\mathrm{a} ; \text { or } \mathrm{p}=\& \mathrm{a}[0] \text {; }
\end{aligned}
$$

Because pointer $\mathrm{p}$ is defined as a pointer variable which points to the two-dimensional array element, so p only can be assigned a element address, not a row address.

b) Using Pointer $p$ to Express Element Address of Two-dimensional Array

After the assignment $\mathrm{p}=\mathrm{a}[0] ; \quad$ or $\mathrm{p}=* \mathrm{a} ; \quad$ or $\mathrm{p}=\& \mathrm{a}[0][0] ;$

there are two forms which use pointer $p$ to express element address of two-dimensional array:
(1) $\mathrm{p}+4 * \mathrm{i}+\mathrm{j}$
(2) $\& \mathrm{p}[4 * \mathrm{i}+\mathrm{j}]$

Among them, $i$ is row subscript of the array, $j$ is column subscript of the array. I and $j$ that appear below is the same meaning with this.

c) Using Pointer $p$ to Express Element of Twodimensional Array

After the assignment

$$
\mathrm{p}=\mathrm{a}[0] ; \quad \text { or } \mathrm{p}=* \mathrm{a} ; \quad \text { or } \mathrm{p}=\& \mathrm{a}[0][0] ;
$$

there are two forms which use pointer $p$ to express element of two-dimensional array:

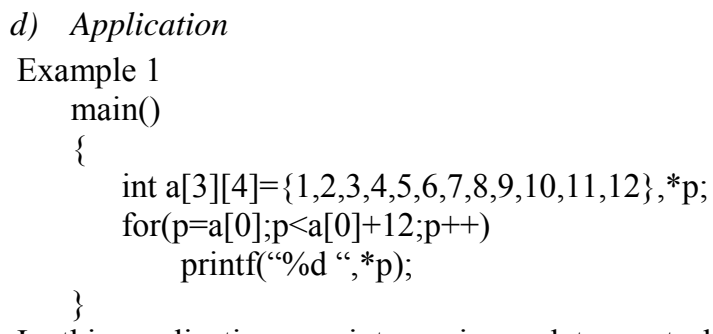

In this application, pointer $\mathrm{p}$ is used to control cycle index. During the cycle process, the value of $p$ is changed,pointer $p$ is moving .Because $p$ is the pointer variable which points to the two-dimensional array element, so after $\mathrm{p}++, \mathrm{p}$ points to the next element.

Example 2 main()

\{

int $\mathrm{a}[3][4]=\{1,2,3,4,5,6,7,8,9,10,11,12\},{ }^{*} \mathrm{p}, \mathrm{i}, \mathrm{j}$; $\mathrm{p}=\& \mathrm{a}[0][0]$ for $(\mathrm{i}=0 ; \mathrm{i}<3 ; \mathrm{i}++)$ for $(j=0 ; j<4 ; j++)$

\{ printf(“\%d ",$* p)$; \} $\mathrm{p}++$;

\}

In this application, $\mathrm{i}$ and $\mathrm{j}$ are used to control cycle index. During the cycle process, the value of $p$ is 
changed,pointer $\mathrm{p}$ is moving. After $\mathrm{p}++, \mathrm{p}$ points to the next element.

Example 3

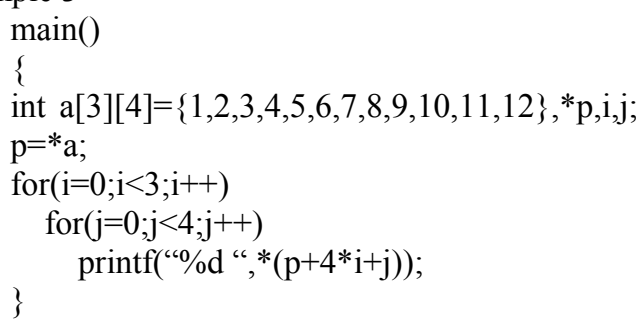

In this application, $\mathrm{i}$ and $\mathrm{j}$ are used to control cycle index. During the cycle process, the value of $p$ is not changed,pointer $\mathrm{p}$ is not moving .

2)The Pointer Variables Which Point to the Onedimensional Array

The pointer variable which points to the onedimensional array is defined as: int a[3][4],(*p)[4];

It should be noted that the size of the onedimensional array which pointer $p$ points to should be equal to the number of columns of the two-dimensional array.

\section{a) Assignment}

Pointer $\mathrm{p}$ points to row zero of the two-dimensional array, the correct assignment is:

$$
\mathrm{p}=\mathrm{a} \text {; or } \mathrm{p}=\& \mathrm{a}[0] \text {; }
$$

the wrong assignment is:

$$
\mathrm{p}=\mathrm{a}[0] \text {; or } \mathrm{p}=* \mathrm{a} \text {; or } \mathrm{p}=\& \mathrm{a}[0][0] \text {; }
$$

Because pointer $\mathrm{p}$ is defined as a pointer variable which points to the one-dimensional array, so $\mathrm{p}$ only can be assigned a row address, not a element address.

b) Using Pointer $p$ to Express Element Address of Two-dimensional Array

After the assignment

$$
\mathrm{p}=\mathrm{a} \text {; or } \mathrm{p}=\& \mathrm{a}[0] \text {; }
$$

there are several forms which use pointer $\mathrm{p}$ to express element address of two-dimensional array:
(1) $\mathrm{p}[\mathrm{i}]+\mathrm{j}$
(2) $*(\mathrm{p}+\mathrm{i})+\mathrm{j}$
(3) $\& p[i][0]+j$
(4) $\& \mathrm{p}[\mathrm{i}][\mathrm{j}]$
(5) $\&(*(\mathrm{p}+\mathrm{i}))[\mathrm{j}]$
(6) $\&(\& p[i][0])[\mathrm{i}]$

c) Using Pointer $p$ to Express Element of Twodimensional Array

After the assignment

$$
\mathrm{p}=\mathrm{a} \text {; or } \mathrm{p}=\& \mathrm{a}[0] \text {; }
$$

there are several forms which use pointer $\mathrm{p}$ to express element of two-dimensional array:
(1) $*(\mathrm{p}[\mathrm{i}]+\mathrm{j})$
(2) $*(*(\mathrm{p}+\mathrm{i})+\mathrm{j})$
(3) $*(\& \mathrm{p}[\mathrm{i}][0]+\mathrm{j})$
(4) $\mathrm{p}[\mathrm{i}][\mathrm{j}]$
(5) $(*(\mathrm{p}+\mathrm{i}))[\mathrm{j}]$
(6) $(\& p[i][0])[j]$

d) Application

Example 4

main()

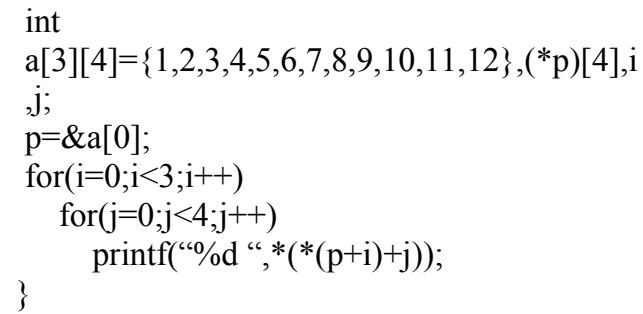

In this application, $i$ and $j$ are used to control cycle index. During the cycle process, the value of $p$ is not changed,pointer $\mathrm{p}$ is not moving .

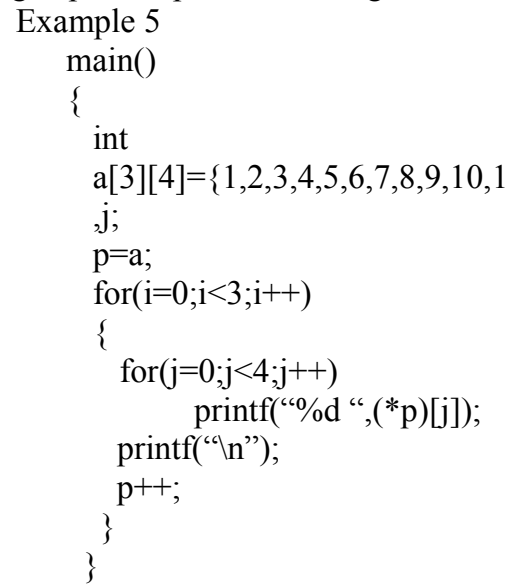

In this application, $\mathrm{i}$ and $\mathrm{j}$ are used to control cycle index. During the outside loop process, the value of $p$ is changed,pointer $p$ is moving. Because $p$ is the pointer variable which points to the one-dimensional array, so after $\mathrm{p}^{++}, \mathrm{p}$ points to the next row.

3) Pointer Array

Pointer array is defined as : int $\mathrm{a}[3][4],{ }^{*} \mathrm{p}[3]$;

It should be noted that the size of the pointer array should be equal to the number of rows of the twodimensional array.

\section{a) Assignment}

Pointer of pointer array separately points to the element of column zero of each row of the twodimensional array, the correct assignment is:

$$
\begin{aligned}
& \text { for }(\mathrm{i}=0 ; \mathrm{i}<3 ; \mathrm{i}++) \quad \mathrm{p}[\mathrm{i}]=\mathrm{a}[\mathrm{i}] \\
& \begin{array}{ll}
\text { or for }(\mathrm{i}=0 ; \mathrm{i}<3 ; \mathrm{i}++) & \mathrm{p}[\mathrm{i}]=*(\mathrm{a}+\mathrm{i}) \\
\text { or for }(\mathrm{i}=0 ; \mathrm{i}<3 ; \mathrm{i}++) & \mathrm{p}[\mathrm{i}]=\& \mathrm{a}[\mathrm{i}][0] \\
\text { the wrong assignment } & \text { is: } \\
\text { for }(\mathrm{i}=0 ; \mathrm{i}<3 ; \mathrm{i}++) & \mathrm{p}[\mathrm{i}]=\& \mathrm{a}[\mathrm{i}] \\
\text { or for }(\mathrm{i}=0 ; \mathrm{i}<3 ; \mathrm{i}++) & \mathrm{p}[\mathrm{i}]=\mathrm{a}+\mathrm{i} ;
\end{array}
\end{aligned}
$$

Because the pointer of pointer array is defined as a pointer variable which points to the element of the twodimensional array, so pointer array element $p[i]$ only can be assigned a element address, not a row address. It should be noted that $p$ is the pointer array name, is not a variable, constructions like $\mathrm{p}=\mathrm{a}$ is illegal.

b) Using Pointer of Pointer Array to Express Element Address of Two-dimensional Array 
After the assignment

for $(\mathrm{i}=0 ; \mathrm{i}<3 ; \mathrm{i}++) \quad \mathrm{p}[\mathrm{i}]=\mathrm{a}[\mathrm{i}]$;

or for $(\mathrm{i}=0 ; \mathrm{i}<3 ; \mathrm{i}++) \quad \mathrm{p}[\mathrm{i}]=*(\mathrm{a}+\mathrm{i})$;

or for $(\mathrm{i}=0 ; \mathrm{i}<3 ; \mathrm{i}++) \quad \mathrm{p}[\mathrm{i}]=\& \mathrm{a}[\mathrm{i}][0]$;

there are several forms which use pointer of pointer array to express element address of twodimensional array:
(1) $\mathrm{p}[\mathrm{i}]+\mathrm{j}$
(2) $*(\mathrm{p}+\mathrm{i})+\mathrm{j}$
(3) $\& \mathrm{p}[\mathrm{i}][0]+\mathrm{j}$
(4) $\& \mathrm{p}[\mathrm{i}][\mathrm{j}]$
(5) $\&(*(\mathrm{p}+\mathrm{i}))[\mathrm{j}]$
(6) $\&(\& p[i][0])[j]$

c) Using Pointer of Pointer Array to Express Element of Two-dimensional Array

After the assignment

for $(i=0 ; i<3 ; i++) \quad p[i]=a[i]$;

or for $(\mathrm{i}=0 ; \mathrm{i}<3 ; \mathrm{i}++) \mathrm{p}[\mathrm{i}]=*(\mathrm{a}+\mathrm{i})$;

or for $(\mathrm{i}=0 ; \mathrm{i}<3 ; \mathrm{i}++) \quad \mathrm{p}[\mathrm{i}]=\& \mathrm{a}[\mathrm{i}][0]$;

there are several forms which use pointer of pointer array to express element of two-dimensional array:
(1) $*(\mathrm{p}[\mathrm{i}]+\mathrm{j})$
(3) $*(\& p[i][0]+j)$
(2) $*(*(\mathrm{p}+\mathrm{i})+\mathrm{j})$
(5) $(*(\mathrm{p}+\mathrm{i}))[\mathrm{j}]$
(4) $\mathrm{p}[\mathrm{i}][\mathrm{j}]$
(6) $(\& p[i][0])[j]$

d) Application

Example 6

$$
\begin{aligned}
& \text { main }() \\
& \left\{\begin{array}{l}
\{ \\
\text { int }
\end{array}\right. \\
& \mathrm{a}[3][4]=\{1,2,3,4,5,6,7,8,9,10,11,12\} \\
& \text { for }(\mathrm{i}=0 ; \mathrm{i}<3 ; \mathrm{i}++) \\
& \mathrm{p}[\mathrm{i}]=\& \mathrm{a}[\mathrm{i}][0] \\
& \text { for }(\mathrm{i}=0 ; \mathrm{i}<3 ; \mathrm{i}++) \\
& \text { for }(\mathrm{j}=0 ; \mathrm{j}<4 ; \mathrm{j}++) \\
& \quad \operatorname{printf}(“ \% \mathrm{~d} \text { “ “* } *(*(\mathrm{p}+\mathrm{i})+\mathrm{j})) \text {; }
\end{aligned}
$$$$
\mathrm{a}[3][4]=\{1,2,3,4,5,6,7,8,9,10,11,12\},{ }^{*} \mathrm{p}[3], \mathrm{i}, \mathrm{j} \text {; }
$$

In this application, $i$ and $j$ are used to control cycle index. During the cycle process, the pointer of pointer array is used to access the element of each row of the two-dimensional array.

4) The Pointer Variables Which Point to the Pointer Array

The pointer variable which points to the pointer array is defined as:

$$
\begin{aligned}
& \text { int } \mathrm{a}[3][4],{ }^{*} \mathrm{p}[3],{ }^{* *} \mathrm{q} ; \\
& \text { for }(\mathrm{i}=0 ; \mathrm{i}<3 ; \mathrm{i}++) \\
& \mathrm{p}[\mathrm{i}]=\& \mathrm{a}[\mathrm{i}][0]
\end{aligned}
$$

a) Assignment

Pointer q points to element zero of the pointer array, the correct assignment is:

$$
\mathrm{q}=\mathrm{p} \text {; or } \mathrm{q}=\& \mathrm{p}[0] \text {; }
$$

the wrong assignment is: $\mathrm{q}=\mathrm{a}$;

b) Using Pointer q to Express Element Address of Two-dimensional Array

After the assignment $\mathrm{q}=\mathrm{p}$; or $\mathrm{q}=\& \mathrm{p}[0]$;

there are several forms which use pointer $q$ to express element address of two-dimensional array:
(1) $\mathrm{q}[\mathrm{i}]+\mathrm{j}$
(2) $*(\mathrm{q}+\mathrm{i})+\mathrm{j}$
(3) $\& q[i][0]+j$
(4) $\& \mathrm{q}[\mathrm{i}][\mathrm{j}]$
(5) $\&(*(\mathrm{q}+\mathrm{i}))[\mathrm{j}]$
(6) $\&(\& \mathrm{q}[\mathrm{i}][0])[\mathrm{j}]$

c) Using Pointer $q$ to Express Element of Twodimensional Array

After the assignment

$\mathrm{q}=\mathrm{p}$; or $\mathrm{q}=\& \mathrm{p}[0]$;

there are several forms which use pointer $q$ to express element of two-dimensional array:
(1) $*(\mathrm{q}[\mathrm{i}]+\mathrm{j})$
(2) $*(*(\mathrm{q}+\mathrm{i})+\mathrm{j})$
(3) $*(\& \mathrm{q}[\mathrm{i}][0]+\mathrm{j})$
(4) $\mathrm{q}[\mathrm{i}][\mathrm{j}]$
(5) $(*(\mathrm{q}+\mathrm{i}))[\mathrm{j}]$
(6) $(\& q[i][0])[j]$

d) Application

Example 7

main()

\{

int

$\mathrm{a}[3][4]=\{1,2,3,4,5,6,7,8,9,10,11,12\},{ }^{*} \mathrm{p}[3],{ }^{*} \mathrm{q}, \mathrm{i}, \mathrm{j}$

for $(\mathrm{i}=0 ; \mathrm{i}<3 ; \mathrm{i}++)$

$\mathrm{p}[\mathrm{i}]=\& \mathrm{a}[\mathrm{i}][0] ;$

$\mathrm{q}=\mathrm{p}$;

for $(\mathrm{i}=0 ; \mathrm{i}<3 ; \mathrm{i}++)$ for $(j=0 ; j<4 ; j++)$ printf(“\%d “,*(*(q+i)+j));

\}

In this application, $\mathrm{i}$ and $\mathrm{j}$ are used to control cycle index. During the cycle process, the value of $q$ is not changed,pointer $\mathrm{q}$ is not moving .

Example 8

main()

\{

int

$\mathrm{a}[3][4]=\{1,2,3,4,5,6,7,8,9,10,11,12\},{ }^{*} \mathrm{p}[3],{ }^{*} \mathrm{q}, \mathrm{i}, \mathrm{j}$;

for $(\mathrm{i}=0 ; \mathrm{i}<3 ; \mathrm{i}++)$

$\mathrm{q}=\mathrm{p}$;

$\mathrm{p}[\mathrm{i}]=\& \mathrm{a}[\mathrm{i}][0]$

for $(\mathrm{i}=0 ; \mathrm{i}<3 ; \mathrm{i}++)$

\{

for $(j=0 ; j<4 ; j++)$ printf( $(" \% d ",(* q)[j]) ;$

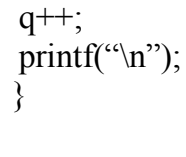

In this application, $i$ and $j$ are used to control cycle index. During the outside loop process, the value of $\mathrm{q}$ is changed,pointer $\mathrm{q}$ is moving . After $\mathrm{q}++$, $\mathrm{q}$ points to the next element of the pointer array $\mathrm{p}$, by reference a pointer of the pointer array to access elements of a corresponding row of the two-dimensional array. 


\section{CONCLUSION}

Using pointer to access the element of twodimensional array, the key is to clear defined pointer points to the element or points to the one-dimensional array. The pointer which points to element is assigned a element address, the pointer which points to the onedimensional array is assigned a row address. After we correctly assign value to pointer and correctly express element of two-dimensional array, we can smoothly use pointer to access the element of two-dimensional array.

\section{REFERENCES}

[1] HaoQiang Tan, C Program Design(The Second Edition) [M], BeiJing:Tsinghua University press,1999（in Chinese ）.
[2]XingHeng He, DongMei Zhang, GaiFang Wang, et al, C Language Program Design [M],BeiJing:China Railway Publishing House,2008 (in Chinese)

[3]YuFen Tu, "The Relation Ships Between Point And Arrays In Language C"[J],Journal of Wuhan Institute of Shipbuilding Technology,2006 (01):36-38 (in Chinese).

[4] Rui Su, ChunFang Zhang,LiWu Wang, C Program Design [M], BeiJing:Tsinghua University press,2009 (in Chinese).

[5]XianGang Chen, YanRu Feng,C Program Design [M], BeiJing:Beijing Institute of Technology press,2007 (in Chinese). 